\title{
Epistemología feminista y digital en el análisis de la comunicación del ciberfeminismo
}

Feminist and digital epistemology in the analysis of cyberfeminism communication

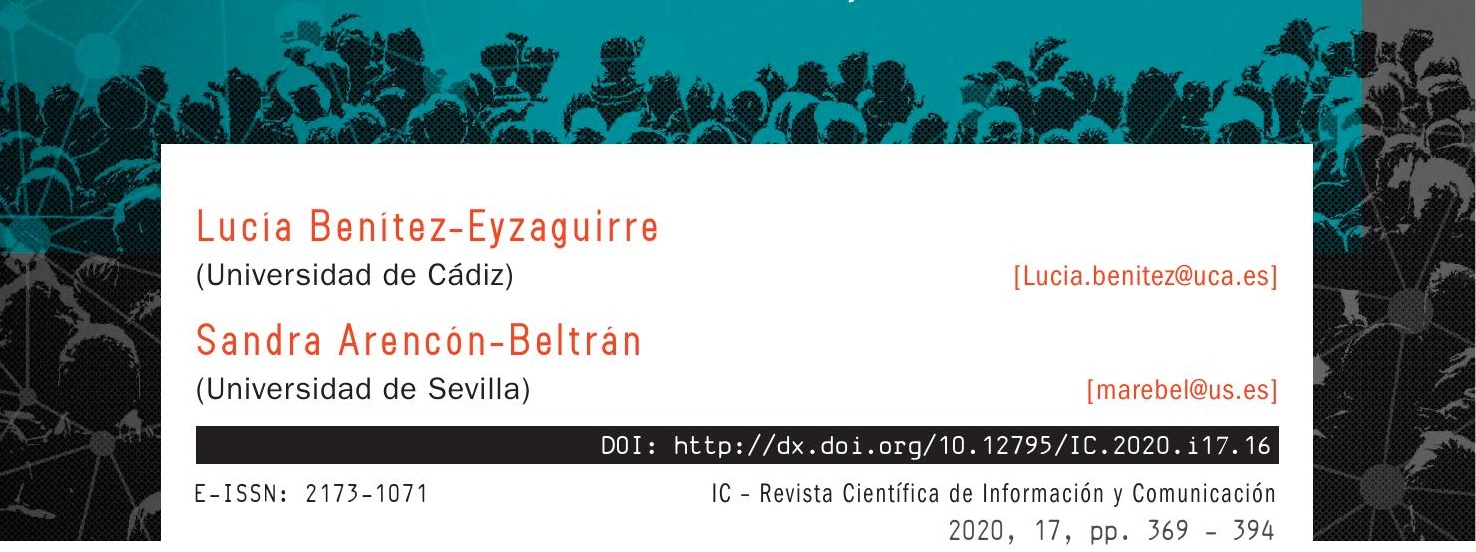
2020, 17, pp. $369-394$

\section{Resumen}

Las movilizaciones feministas más recientes muestran la emergencia de la demanda de la justicia y la igualdad de las mujeres con la ocupación sistemática y cada vez más intensa del espacio digital y el espacio público. Para el análisis de este fenómeno, se busca un marco conceptual coherente, a partir de la epistemología feminista y digital como una revisión crítica y sistemática del conocimiento racionalista y de la investigación positivista.

\section{Abstract}

The latest feminist mobilizations show the emergent demand of women for justice and equality on the systematic and intense occupation of the digital space and the public space. A coherent conceptual framework is sought, in order to analyse this phenomenon; one that is based on feminist and digital epistemology as a critical and systematic review of rationalist knowledge and positivist research.

\section{Palabras clave}

Metodología feminista; epistemología digital; género; movimientos sociales; conocimiento situado; cuerpo. 


\section{Keywords}

Feminist methodology; digital epistemology; gender; social movements; situated knowledge; body.

\section{Sumario}

1. La perspectiva de género en la comunicación

2. Una epistemología crítica

3. La centralidad de la epistemología feminista

4. La teoría del punto de vista y el conocimiento situado

5. La investigación sobre los cuerpos y lugares en la expresión política

6. Epistemología digital

7. Lo colectivo y lo común en la epistemología

8. La negociación de las identidades, entre el género y la ideología

9. La investigación acción y feminista de los movimientos sociales. 10.- Modelos de investigación feminista

11. Bibliografía

\section{Summary}

1. The gender perspective in communication

2. A critical epistemology

3. The centrality of feminist epistemology

4. The theory of point of view and situated knowledge

5. Research on bodies and places in political expression

6. Digital epistemology

7. The collective and the common in epistemology

8. The negotiation of identities, between gender and ideology

9. Action and feminist research of social movements

10. Feminist research models

11. Bibliography 


\section{La perspectiva de género en la comunicación}

La perspectiva de género incorpora criterios de equidad y justicia, una visión hacia las personas y las oportunidades sociales que integra dimensiones como la democratización, la paridad, la sostenibilidad, la participación o la interculturalidad. Respecto a la comunicación desde la perspectiva de género, presenta un gran potencial para mostrar la realidad: "Los medios de comunicación y la teoría de género se han convertido en elementos clave para explicar y explicarnos el mundo en que vivimos" (Moyá, 2009, p. 2). Sin embargo, en la práctica la incorporación de la perspectiva de género a la ciencia de la comunicación ha sido limitada y simbólica. La investigación se ha centrado en los estudios sobre producción, estructura de los medios, políticas de representación de mujeres y de la diferencia, así como en el análisis de contenidos, dejando a un lado interrogantes sobre la financiación a través de una publicidad que exprime el sexismo, el origen y la causa misma de su existencia y otras cuestiones dirigidas a la transformación real de las desigualdades y la promoción de la autonomía. (Benítez-Eyzaguirre, 2016). Sus avances son también limitados en el diseño de políticas comunicativas, así como en el estudio y las posibilidades de los modelos participativos de comunicación desde una perspectiva de género. En el contexto digital, hay que contemplar que de nuevo se intensifican las brechas comunes a la estratificación social como son la geopolítica, la social, la formativa, la laboral, la de renta, clase social y tiempo de ocio (Bonder, 2007, pp. 7-9).

Tanto el vocabulario como el enfoque con perspectiva de género presentan claves y estrategias para el análisis de la realidad como una apertura a la diversidad, a la visión social, de inserción, a partir de lo comunitario y colectivo. Se valora la subjetividad como dimensión humana de la comprensión de la realidad y se incorpora el concepto de intersubjetividad como un significado compartido en el contexto de las interacciones, fruto de un proceso negociado que incorpora matices y divergencias para enriquecer la significación de conjunto. La perspectiva de género supone por tanto la detección de los problemas de sexismo en la investigación y la gestión de lo cotidiano, donde atender a las prácticas abusivas, los clichés, las dinámicas y estereotipos establecidos por el patriarcado y que se enquistan como formas estables de ver el mundo. 


\section{Una epistemología crítica}

El planteamiento crítico es imprescindible en el estudio de las transformaciones y la institucionalización de los movimientos sociales ya que supone una revisión del conocimiento desde la interrogación de la producción académica y científica registrada hasta ahora. Se plantea aquí la necesidad de una epistemología de género y de la tecnología en la configuración del sistema cultural en el que se registran las dinámicas y valores sociales sobre el reconocimiento de la igualdad como supuesto básico esencial de las reivindicaciones de las movilizaciones.

El punto de partida es un paradigma teórico interpretativo de corte fenomenológico desde el que se puede comprender la subjetividad de las mujeres en la construcción de su agenda de género coherente con la movilización social, pero a la vez un encuadre socio-crítico orienta el análisis de la evolución en la conciencia de los derechos de género por parte de los colectivos que han participado en el ciclo de movimientos sociales abierto a nivel global en 2011.

La posición crítica tanto en las aportaciones conceptuales como la investigación es coherente con la epistemología y la metodología de género y feminista, ya que de forma reflexiva se cuestiona tanto la capacitación como el conocimiento sobre tecnología, así como el binarismo de género. Con ello, se sobrevuela sobre cuestiones lingüísticas y el construccionismo que refuerza, por la inclusión de las mujeres, el binarismo de género para girar hacia la representación plural que incluye a las mujeres en los discursos. La perspectiva de género es más amplia y diversa que la oposición masculino/femenino como patrón de análisis de la identidad simplificador y excluyente. Coincidimos con la visión de Benhabib (2006, p. 272) sobre una construcción alternativa del lenguaje:

Si es imposible pensar, de acuerdo con dicha tradición, sin oposiciones binarias, entonces la tarea de la lectura feminista se convierte en la articulación no de un nuevo conjunto de categorías, sino de hacer trascender el discurso categórico por completo. Una debe buscar no un nuevo lenguaje, sino un discurso en los márgenes del lenguaje.

Hay que responder a qué significa ser mujer o ser invisible para el conocimiento, o cuál es la información útil para las mujeres, o de qué forma se transforma la realidad cuanto se producen visiones alternativas fruto de otras posiciones sociales y políticas. A 
la vez hay que plantearse cuál es el papel de la tecnología en nuestra forma de acceder a la información significativa, a la construcción de la comprensión del mundo y de la realidad, al entender que el sistema cultural y social en el que hay que fundamentar el análisis de las dinámicas y valores que influyen en la posición y el reconocimiento de las mujeres. Esta epistemología feminista y digital enmarca el análisis de la subjetividad, la evolución y los cambios registrados en la percepción de los derechos de los colectivos de quienes participan de las movilizaciones.

\section{La centralidad de la epistemología feminista}

El paradigma fenomenológico o humanista apuesta por las interpretaciones cualitativas basadas en la significación, en la interconexión de los hechos y las diferencias. Coincide con la premisa esencial feminista sobre el conocimiento que se percibe a través de una perspectiva humana y que, por tanto, hay una integración permanente entre las personas que investigan y el objeto de estudio, en la práctica crítica y constructiva. Así, se conecta la acción como fuente de conocimiento con las formas de pensar e imaginar el mundo de los propios actores sociales, se establece una relación dialógica y permanente entre la realidad y lo conocido o entre objeto y sujeto.

Haraway (1995) mantiene que el planteamiento feminista respalda la fiabilidad y la solidez de la investigación, por cuanto se trata de una teoría crítica sobre las formas del saber que favorece la contestación, la deconstrucción, las conexiones entrelazadas y otra forma de mirar la realidad. Apuesta por un cambio en la "doctrina y una práctica de la objetividad que favorezca la contestación, la deconstrucción, la construcción apasionada, las conexiones entrelazadas y que trate de transformar los sistemas del conocimiento y las maneras de mirar" (Haraway, 1995, p. 329). También la Comisión Europea (2011) defiende que el análisis de las variables de género como de mayor calidad en la indagación, garantía de fiabilidad y solidez de la investigación en cuanto teoría crítica que cuestiona las formas del saber y la objetividad, entendida como una doctrina de la apropiación de la realidad construida desde el positivismo, con la que se ha operado contra las mujeres y los otros.

La epistemología feminista se teje en un campo de tensiones y de redefinición paralelo e integrador a un conjunto amplio de posiciones críticas sobre la ciencia y el conocimiento que concretó Sandra Harding (1995, pp. 76-82), a partir del trabajo de Millman y Kanter (1975). El campo de estudios cuestiona las consecuencias de la 
producción de una ciencia masculina y se resume en cinco cuestiones básicas. De una parte, el resultado de una ciencia que ha priorizado las temáticas e intereses de los hombres sobre las mujeres y sobre necesidades colectivas. Como ejemplo se puede citar la sistemática ignorancia de las emociones o del trabajo y la riqueza que surge de las actividades y creencias de los hombres. En segundo lugar, se identifica la división entre lo público y lo privado como base del conocimiento situado ocultando los efectos de las interacciones sociales y de la comunidad en la creación de la estructura social. En tercer lugar, se ha venido asumiendo una sociedad única sin género, simplificada con generalizaciones, sin atender que afecta a la conceptualización de las ciencias sociales, de la propia estructura social y hasta de los límites de la disciplina: "Gran parte de lo que los hombres consideran "naturaleza" -en oposición a "cultura"-, para las mujeres, pertenece a la "cultura"” (Harding, 1995, p. 78), y añade: "Lejos de habitar en una sociedad única, parece que las mujeres y los hombres viven en mundos diferentes. Pero las ciencias sociales solo tienen en cuenta el mundo de los hombres como si fuese el único mundo social" (Harding, 1995, p. 79). Cuando no se tiene en cuenta el sexo como un elemento explicativo de la conducta, añade en cuarto lugar, se termina entendiendo que el género es una cuestión que afecta solo a las mujeres. Por último, la crítica a las metodologías y posiciones investigadoras que limitan el acceso sistemático a una parte de la información. Por ejemplo, la sospecha de que la definición del trabajo se realice en función de variables y no respecto a las personas, correspondería a un estilo masculino de manipulación que considera de forma muy prioritaria las situaciones y los actores oficiales. Esta crítica a las pretensiones de neutralidad de la ciencia, lo es por extensión a los valores, la objetividad y la racionalidad de las ciencias sociales, que han venido olvidando la conducta, la pobreza explicativa de las generalizaciones, o el ocultamiento de un sesgo fundamental: "la sociología se ha centrado en los personajes y definiciones de la situación públicos, oficiales, visibles, espectaculares o todos ellos; sin embargo, las esferas no oficiales, de apoyo, menos espectaculares, privadas e invisibles de la vida y de la organización sociales pueden tener la misma importancia” (Millman y Kanter, 1975, p. X).

La perspectiva feminista muestra interpretaciones diversas capaces de recoger las turbulencias de los procesos sociales, los esquemas sistémicos y multidimensionales de la configuración de los movimientos sociales, los elementos relacionales de la conectividad social y tecnológica, todo ello desde la identidad y perspectivas humanas como las emociones o las expectativas, factores claves de la dimensión política de las personas. Massey (2005, p. 126) propuso un cambio radical al proponer una política relacional, al 
margen de las identidades ya constituidas, es decir, no como una política de identidad al estilo norteamericano. La idea se centra en una política que muestre el poder que pesa sobre las identidades, como una política real sobre el poder de las identidades.

\section{La teoría del punto de vista y el conocimiento situado}

La construcción de otra epistemología no solo ha cuestionado el conocimiento consolidado y su pretendido valor social, sino que es una práctica de resistencia fruto de la necesaria reflexibilidad de la investigación que incluye los valores del contexto de la indagación porque todo ello muestra otras realidades primero en su propia justificación, pero también, y mucho más importante, en los propios resultados que aporta. En esa dirección, Biglia y Jiménez (2012) mantiene que solo un análisis que muestre cómo interviene el género en la producción de saberes responde a la política feminista, no hacerlo así se convierte en una declaración de intenciones, de posicionamientos, una cuestión autorreferencial que estaría vinculada a la individualidad neoliberal. Dos grandes teóricas de esta temática, Haraway (1995) y Sandra Harding (1995), coinciden al señalar la teoría del punto de vista como el mejor enfoque para cuestionar el carácter situado de las creencias, e incluso las epistemologías posmodernas que se debaten en las contradicciones del relativismo y el compromiso político. Harding (1987, pp. 8-9) se anticipó cuando entendía el conocimiento como parcial y según la situación y contexto. Lo ilustró con el ejemplo del cambio radical que experimentaron los estudios psiquiátricos a la hora de definir la conducta femenina y de comprenderla desde que las mujeres comenzaron a estudiar la mentalidad y las conductas de los psiquiatras masculinos.

Por su parte, Haraway (1995, p. 329) construye una teoría del antirrelativismo a través de "los conocimientos parciales, localizables y críticos, que admiten la posibilidad de conexiones llamadas solidaridad en la política y conversaciones compartidas en la epistemología" que produce una falsa universalidad, al entender el valor de la conexión parcial de los conocimientos y del pensamiento crítico; "necesitamos un circuito universal de conexiones, basado en la habilidad parcial de traducir" (Araiza, 2013). El conocimiento situado, como vemos, permite cuestionar las características sociales ligadas al sexo y por tanto la posición de las mujeres en la construcción de lo social, económico y político. 
La crítica al binarismo de género en la geografía se enfoca sobre cómo el espacio aparece ligado a lo privado y femenino, a lo emocional, mientras que el tiempo lo hace a lo político, racional y masculino (Radcliffe 1993). Por ello, Doreen Massey (1992, p. 76) cuestiona los dualismos en la formación y funcionamiento del poder, para aportar relaciones alternativas más liberadoras a través de su idea de la multidimensionalidad que incorpora el espacio y el tiempo como entrelazados entre sí a través de su propio equilibrio. Incluso llega a entender que solo se puede hacer política en la comprensión de un futuro abierto:

rechazar la temporalización del espacio abre nuestras historias a la multiplicidad y permite reconocer que el futuro no está escrito de antemano, sino que, al menos en cierto grado y dentro de las condiciones que imponen las circunstancias que no elegimos, está en nuestras manos construirlo (Massey, 2005, pp. 126-127)

Es así como entiende que el espacio es una parte esencial de la constitución y del proceso de lo político, de las subjetividades antiesencialistas, alejadas de lo inmutable, y más próximas a una concepción relacional del mundo (Massey, 2005, pp. 106-108). Entiende que el espacio crea diferencias, integra trayectorias diferentes y acoge la multiplicidad: "El espacio, para decirlo una vez más, es el producto de interrelaciones" (Massey, 2005, p. 119).

También para Lefebvre (2013, p. VII) el espacio es tan político como ideológico porque despliega modelos militares y políticos de estrategia: "mediante la acción del poder, el espacio practico porta en sí normas y obligaciones. Más que expresión del poder, es la represión en nombre del poder (y a veces en nombre de nada). Suma de coacciones, estipulaciones y prescripciones, el espacio social adquiere esta eficacia normativa-represiva”. El pensamiento de Lefebvre, así como el de otras geógrafas, explica el factor espacial en la expresión pública de la resistencia y la protesta porque es donde se articulan conflictos políticos económicos y sociales, como en una relación dialéctica entre el Estado y los movimientos sociales (Mouffe 1995). A su vez, "La eficacia de las prácticas sociales en la vida social [...] adquieren sus significados en las relaciones sociales específicas de clase, género, comunidad, etnicidad o raza y 'se agotan' o ‘modifican' en el curso de la acción social” (Harvey, 1990, p. 247) 


\section{La investigación sobre los cuerpos y lugares en la expresión política}

La investigación feminista asume la propuesta de Donna Haraway en Ciencia, cyborg y mujeres (1995) sobre el reconocimiento de los sesgos que se registran en lo personal, la epistemología y en el carácter simbólico del conocimiento. Todo ello conduce a un planteamiento diverso y a la apertura a los significados múltiples, que sintetiza Linda McDowell en Género, identidad y lugar (2000, pp. 329-363) a través de matrices sobre los objetos, la metodología, los puntos de vista, como una crítica a la epistemología fruto de la ciencia tradicional y racionalista. Se centra en la situación espacial y el punto de vista para la revisión de los esquemas tradicionales ligados al espacio, que no incorporan en su análisis aspectos dinámicos, flexibles o sobre la complejidad, a la vez que las dimensiones materiales, culturales, simbólicas y subjetivas. La perspectiva de género aporta la subjetividad, la emoción y visiones alternativas a los sistemas de poder -dentro de la complejidad y la diversidad que la caracteriza-, como un conjunto de relaciones sociales y formas de representación que permitan transgredir las antiguas divisiones (McDowell, 2000, pp. 322-327).

Además de plantear el conocimiento situado y las opciones de expresión política, afronta también la toma de decisiones personales como cartografía desde la que cambiar y cuestionar el poder, las normas y el control social: "Así, (dis)poner al cuerpo a hacer política, supone transitar por nuevas situaciones, exponerse (arriesgarse y mostrarse) para escuchar y proponer al cuerpo y a nuestros deseos... y estar dispuestas a asumirlo también físicamente" (Ema-López , 2006, p. 120). Así, junto a la dimensión espacial, la corporal cobra una especial significación con la sociedad de consumo, como viene defendiendo Wajcman (2006, p. 171):

Los análisis postmodernos han identificado acertadamente el cuerpo como emplazamiento donde cada vez más tiene lugar una acumulación de capital, y no solo la reproducción. Los nuevos regímenes corporales se consideran un elemento clave de los procesos de identidad personal. [...] El feminismo cyborg considera que estas tecnologías potencialmente disuelven el nexo sexo/género en la hibridación del cuerpo sexuado vivido y las máquinas. 
En la investigación situada, la dimensión espacial toma protagonismo cuando los cuerpos se entienden como espacio de resistencia. El cuerpo en relación con la tecnología y, en especial, en su dimensión política y en la performatividad ocupa el análisis teórico de Haraway o de Judith Butler (2015). Sobre su dimensión política ya escribió Lefebvre (2013, p. 247) y la propia Butler (2015, p. 96), cuando defiende la dimensión política en simultáneo a la tecnología:
¿Pueden los actos del cuerpo separarse de la tecnología?; ¿Acaso no está la tecnología colaborando en el establecimiento de nuevas formas de acción política? Cuando la censura y la violencia actúan directamente contra los cuerpos, ¿no se está obrando también contra el acceso a los medios con el fin de ejercer un control hegemónico sobre la difusión de imágenes?

La biopolítica se relaciona con la subjetividad, con el autocontrol de la vida, y con la capacidad de ejercer una producción biopolítica del orden, como ya defendieron Hardt y Negri (2004, p. 24), a partir de las conexiones entre el mundo simbólico, la comunicación, el lenguaje que realizan los medios de comunicación y que han venido articulando las luchas políticas (Melucci, 1996). El cuerpo alcanza dimensión política en la resolución de las cuestiones cotidianas en las que se reproduce el orden y el poder y donde también se cuestiona la acción individual y colectiva:

La [producción política de la] vida, se convierte en un terreno prioritario para las resistencias y transformaciones políticas. Y si la vida cotidiana es un terreno de despliegue del (bio)poder, también lo es de la potencia que no se somete al control y gobierno. Se trata de politizar, por tanto, las propias experiencias cotidianas de semiosis, interacción y producción de (significados sobre) el mundo y su encarnación corporal como afectos (Ema-López, 2006, p. 120)

La dimensión física de las personas en relación con la tecnología, con la epistemología digital, en el mismo sentido que ha definido Carlos Scolari (2018) al abordar la cuestión de la interfaz mucho más allá del dispositivo, no como interfaz de usuario, de relación e interactividad con el dispositivo digital. Scolari traslada este concepto para explorar la interactividad en todos los procesos tecnológicos y digitales, como un 
espacio relación. Toma la idea de Pierre Lévy, cuando escribió: “La interfaz reenvía a las operaciones de traducción, de puesta en contacto con ambientes heterogéneos. En este sentido, evoca a la comunicación (o al transporte) y a los procesos transformadores necesarios para el éxito de la transmisión" (Lévy en Scolari, 2018). Se entiende la interfaz es el espacio de la interacción con los demás, un área amplia e indeterminada de relación no solo entre humano y máquina, sino mucho más allá, en donde se fragua la expresión más personal y política de la subjetividad, a través del cual conectamos con otras formas de entender el mundo.

Las prácticas biopolíticas en los contextos virtuales forman parte de un proceso de desterritorialización tanto de los cuerpos como de la realidad social, a pesar de que las acciones en el mundo digital se vinculan y entrelazan con las interacciones cara a cara según un modelo de organización sin mando. La red se convierte en un entramado biopolítico determinante para las acciones colectivas en función de la información, la conexión o la manipulación ya que también actúa como un dispositivo de vigilancia y control en el que se redefine el concepto de poder en acciones que pueden alcanzar una dimensión global o bien de relacionar datos o información. Esta estructura de la red ha supuesto una apertura y un enriquecimiento para el feminismo que incorpora nuevos temas, pero también nuevos sujetos políticos "en la intersección entre la comunicación digital deslocalizada y la experiencia de los cuerpos" (Rovira-Sancho, 2018, p. 230).

\section{Epistemología digital}

Haraway, a través de las disciplinas de su compromiso feminista, la epistemología y la biología, aborda el estudio de la cibernética como un campo interdisciplinar de los sistemas reguladores ya que estudia la conectividad, los sistemas de comunicación y de regulación tanto de los sistemas físicos como de los sociales, de lo seres vivos y de sus imitaciones en máquinas y organizaciones. La cibernética está ligada tanto a la teoría del control como a la teoría de sistemas, por ello, Haraway consigue una visión revolucionaria de la regulación de los sistemas, de la retroalimentación a través de las funciones del control y de la comunicación. Así es como traslada lo orgánico a lo mecánico para cuestionar dualismos como los que se registran entre la estructura y la función o bien entre la forma y el proceso (García-Selgas, 1995, p. 25). Son cuestiones esenciales sobre la teoría del conocimiento y las formas racionales que hacen aflorar cuestiones invisibles para el análisis de la relación entre género y comunicación. 
La epistemología digital entiende que el nuevo espacio no material sino virtual tiene un poder estructurante en la vida de las personas. Este planteamiento crítico parte del supuesto de que si la conectividad dibuja un escenario de interrelación compleja donde todas las dimensiones macro y micro están en juego, hay que atender a las formas en que Internet afecta a nuestros modos de comprensión, a la influencia de la interfaz entre sujetos, las redes digitales de poder, o su velocidad. De hecho, la estructura de la red es con la que se interrelacionan las personas, y a la vez una referencia para comprender la realidad de otra forma, dibuja otras formas de relación y un nuevo modelo social; la 'sociedad red' que definió Castells (2005). Con este referente, podemos comprender de otra forma el poder, la estructura social, la velocidad e instantaneidad de las relaciones, incluso las formas de producción y expansión del conocimiento.

Las características dominantes de la digitalización de la política, según ha señalado Battochinio (2014), están marcadas por activistas cuyo origen social no está relacionado con su estatus o con sus posiciones estructurales y pasan por unas prácticas más horizontales, descentralizadas y difusas, tanto en la organización como en la toma de decisiones, el debate alrededor de un mayor pluralismo de ideas y político pero centrado en demandas sobre las formas de estar en el mundo y las maneras de vivir, así como por unas posturas de reivindicación pacíficas y no violentas.

Cabe plantearse cuál realidad es la que queda afectada por todo ello; si es la realidad física y sensorial y la realidad virtual como recreación del mundo sensible $y$, por tanto, producida por el propio proceso de digitalización. Todo ello conduce a la necesidad de integrar Internet en la comprensión de la realidad y de lo cotidiano (Ursua, 2013), aunque las prácticas comunicativas señalan una doble espacialidad, entre el mundo online al offline, entre las que se negocian tanto la identidad como la ideología. Por tanto, la epistemología digital o tecnológica será el marco conceptual para la producción del conocimiento en el contexto de la digitalización de la vida cotidiana y de las prácticas comunicativas.

La epistemología digital revisa el conocimiento a partir de un nuevo espacio no material, el mundo digital, y su poder estructurante en las vidas de las personas: "La relación Lenguaje, Sujeto, Discurso, Poder y Sociedad digital hay que pensarla en redes y con visión crítica en este siglo XXI" (Merejo, 2015). Por su parte, Silva-Moreira (2004, pp. 223-233) enumera los aspectos que se ven afectados por la digitalización, los objetos y fenómenos por conocer, el mismo concepto del conocimiento y los procesos para alcanzarlo, incluida la propia persona que conoce, y el significado y el equilibrio entre los distintos modos de conocer. Nuevas herramientas, realidades y medios posibilitan 
repensar la forma en que se produce el conocimiento para así reinventar discursos, modelos de análisis de fenómenos inmateriales, a partir de la existencia consolidada y duradera en que se consolida la existencia digital.

De hecho, Manovich (2014, pp. 292-293) cuestiona el conocimiento a través del desarrollo del metamedio informático que condiciona la forma de interactuar con los medios y las técnicas de producción del conocimiento, para proponer una epistemología del software referida a la conversión de la información en datos y en el uso de algoritmos que puede "generar nueva información de los datos viejos ya analizados". De esto se desprende que las capacidades humanas estarán en función de la mejora del software y del desarrollo de una cultura digital.

\section{Lo colectivo y lo común en la epistemología}

El conocimiento tiene una dimensión colectiva en su propio origen, en su desarrollo acumulativo que permite el avance común. Los conocimientos ancestrales, fruto de experiencias comunes y dilatadas en el tiempo, son la base sobre la que se desarrollan nuevas ideas, sobre la realidad social multidimensional y compleja que resultaría inabarcable de otro modo; su concreción se logra a través del debate y el consenso, el hallazgo de las explicaciones sobre las que construir una visión común. La acción y sus teorías ponen en evidencia los intereses comunes en la transformación de la realidad cuando a partir de una situación problemática se obtiene conocimiento concreto e incluso experiencias sociales de cambio. En el proceso, se consigue la identificación de las relaciones en la realidad social, se obtiene el reforzamiento comunitario de un proceso dialógico por el que el colectivo construye sus teorías y soluciones (Hall, 1983). De la misma forma, Freire (1975) mantiene la importancia del diálogo en comunidad para aprender a participar en experiencias comunitarias, para fomentar actitudes solidarias y de compromiso con los valores y necesidades colectivas, que al cabo les convierte en actores protagonistas de la historia. A través del diálogo y la ayuda mutua, la unidad entre el trabajo manual y el intelectual se generan nuevas formas de comportamiento conscientes de los problemas de desarrollo endógeno.

La epistemología clásica se ha consolidado a través de estrategias individuales e individualistas, como si conocer, pensar, creer, fuera solo fuera un proceso personal, pero la estructura conectiva de la sociedad red pone de manifiesto la importancia de los procesos, a menudo ocultos, que añaden valor y riqueza a los fenómenos sociales. 
Ahora, como nunca antes, se conocen patrones de distribución, autoorganización, o de relación que se conocen como sistemas emergentes (Johnson, 2003). Estas evidencias nos sitúan ante la realidad, hasta ahora inexplorada, de entender la sociedad como un organismo vivo y sistémico que responde a patrones macro en su evolución y cambio, en la adaptación a las nuevas posibilidades contextuales.

La inteligencia colectiva o el conocimiento social necesitan una epistemología dentro de la existencia digital en la que se contemple tanto el mundo sensible como las redes de poder digitales, la fiabilidad de las interfaces en la relación entre sujeto, el condicionamiento de la velocidad y la eficiencia de las redes (Ursua, 2014).

\section{La negociación de las identidades, entre el género y la ideología}

En sí mismo, el propio concepto de movimiento social resulta tan complejo, teórica y analíticamente, que, al convertirse en el centro de la acción y el cambio social, la ambivalencia y pluralidad de las experiencias existentes dificultan conceptualmente su identificación, tanto desde el análisis como entre los propios sujetos y actores participantes. Diani (1992) propone para su estudio cuatro aspectos básicos: la constitución y organización informal en redes; la construcción de valores y creencias compartidas; el desarrollo de la acción compartida en áreas de conflicto; y la independencia de las actividades del colectivo frente a la esfera institucional. Con un enfoque más generalista, destaca tres características como parte de sus señas de identidad: la racionalidad estratégica en la coordinación de esfuerzos y la movilización de recursos; Ias nuevas formas organizativas que garanticen la cooperación asociativa; y la reflexividad como toma de conciencia sobre el papel y los factores determinantes en el juego de poderes que marca la actividad de estas organizaciones.

La pertenencia a una identidad colectiva refuerza la identidad personal, de la misma forma que la acción construye los proyectos colectivos. Por tanto, todo movimiento social siempre es más que lo que la organización abarca, se caracteriza por un sentimiento de nosotros, y un carácter simbólico; genera signos que fortifican su integración y consolidan la identidad de sus miembros (Raschke, 1994). Quienes participan en un movimiento social actúan a partir de la información que a menudo el propio grupo les proporciona, y son las mediaciones las que determinan su actitud, sus aspiraciones y su comportamiento. La interacción del grupo, en sus dimensiones 
culturales y normativas, es la base de referencia de los miembros del movimiento social por oposición a otras instituciones y organizaciones sociales.

Los movimientos sociales, que contribuyen a la transformación social con su visión dinámica, se constituyen sobre su propia estructura de organización y manifestación en función de características latentes, simbólicas o imaginarias. La importancia de la acción social se determina según los actores entienden las señas de identidad, entendidas de forma fluida, es decir, más como proceso que como producto. Las dimensiones que componen el proceso identitario, según Melucci (1994), serían las del conocimiento, las relacionales entre los actores y las inversiones emocionales, las plusvalías afectivas que transfieren en la acción colectiva y su conocimiento dichos actores. A pesar de la importancia que en el proceso juega la negociación, el movimiento social nunca es fruto por completo de esa negociación, es decir, nunca es negociable por completo ni surge del cálculo de los costos y beneficios (Melucci, 1999, p. 66).

El feminismo logra su constitución como actor político en el momento en que cuestiona las categorías de hombre y mujer, según la diferencia de poder. Así pasa al ámbito público y al campo de batalla la cuestión, como un reclamo de "la libertad de la necesidad, no la lucha por la igualdad, sino por la diferencia, no ya la libertad de hacer, sino la libertad de ser" (Melucci, 1999, p. 133). Es la forma que tienen los movimientos sociales de resultar eficaces a una causa, cuando sitúan en la esfera pública una cuestión como una acción solidaria que se resuelve a partir de un conflicto (Melucci, 1994), y lo hace a partir del cambio de los códigos simbólicos, que desafíen a los dominantes.

\section{La investigación acción y feminista de los movimientos sociales}

A modo de hipótesis, se puede plantear que si entendemos el ciberespacio como un lugar en el que la identidad no está ligada al contexto físico ni a los condicionamientos culturales y sociales, a los sistemas de opresión, de exclusión o discriminación, se trata de un lugar con las condiciones más óptimas para interpretar desde la teoría de género la construcción social y cultural de las categorías formadas en los procesos de organización política, social o económica a lo largo de la historia. Podemos, en ese caso, entender el mundo digital como un espacio de resistencia para la construcción de una agenda de género, una vía política de la vida propia, en un contexto 
radicalmente diferente en el que construir identidades alternativas sin el peso de los factores culturales, biológicos o políticos.

Para la investigación de los movimientos feministas en el contexto de los nuevos movimientos sociales, se parte de la premisa metodológica de que las mujeres que participan en ellos tienen capacitación y destrezas tecnológicas y sociales como personas activas de la vida social y política. Para esta situación contextual, Amaia Pérez-Orozco (2006, p. 150) recomienda una "elección contextualizada y estratégica de los métodos, sin establecer fronteras previas al análisis", a la vez que una estrategia interdisciplinar para abordar desde el diálogo. De hecho, recuerda cómo Harding defiende que las construcciones teóricas a menudo solo representan una parte de la realidad. Para investigar estas cuestiones, interesa conocer sus experiencias, opiniones, discursos sobre su empoderamiento feminista como un proceso en el que se construye una agenda propia de derechos de género, al margen de los valores dominantes.

El paradigma interpretativo-fenomenológico con el que se aborda la cuestión es coherente con la epistemología y metodología de género y feminista. Con un planteamiento reflexivo y crítico se puede cuestionar a la vez tanto los cambios en la agenda de género, la capacitación y el conocimiento del mundo digital y las acciones políticas a través de un estudio cualitativo de corte sociocrítico para atender a la complejidad por encima de las clásicas relaciones causa-efecto. Al margen de la causalidad, se descubre la comprensión integral y procesual, la estructural de las experiencias que se transforma en un conocimiento fundamental. Una estrategia inductiva, opuesta a la investigación positivista, tiene una gran capacidad generadora de innovación mucho más si se combina con un proceso de análisis y codificación abierta, en la aplicación de la Grounded Theory, que finalmente marcará la influencia y relaciones entre la estructura y conceptos del análisis y el contexto. El análisis inductivo de la información muestra conceptos emergentes que pasan a ser representativos cuando se relacionan entre ellos a través de códigos o variables, mucho más en relación con el contexto social y territorial, como investigación situada.

Se acompaña del aprendizaje colectivo en el análisis crítico participado por la comunidad y orientado siempre al cambio social. Así, combina teoría y práctica con la toma de conciencia que conduce a la movilización colectiva para la transformación, en un proceso de empoderamiento (Eizagirre y Zabala, 2006) y de cambio cultural, en el que el colectivo cambia desde la demanda y la reivindicación hacia la autoorganización para la construcción colectiva de la resolución de problemas. Se trata de la Investigación Acción Participativa (IAP) que propone una estrategia dialéctica orientada 
a la transformación social colectiva, concibiendo el conocimiento como un proceso de emancipación de todos, con todos y para todos. El rigor y la crítica hacen de este tipo de modelos de investigación e intervención social un planteamiento sólido orientado a resolver problemas en su propio origen y en sus efectos, a través de una metodología que cuestiona la relación entre los miembros, los intereses y la atención a los colectivos excluidos, sino que además como proceso tiene el cometido, como enseñara Freire, de facilitar que los sujetos puedan escribir su propia historia. La marginación de los destinatarios es una lógica de dominación por parte de dirigentes y técnicos que buscan mayor influencia sobre las minorías pasivas.

Los objetivos de esta metodología están interrelacionados: la producción común del conocimiento, el estudio colectivo de la información y de su uso, el análisis crítico, y las relaciones entre los problemas individuales y comunes. Así se logra la democratización del conocimiento y se aspira a la cohesión interna de la comunidad ayudando a descubrir problemas y a razonar sobre las soluciones. El método aborda diferentes planos como la promoción colectiva, la creación de conciencia y la difusión del conocimiento, a través de una herramienta de motivación, que busca la participación activa y democrática de la población para liderar su visión del desarrollo local (Durston y Miranda, 2002). La investigación así concebida es una práctica crítica que conduce a la realización emancipadora de los proyectos, imaginarios y objetivos. Todo ello porque en el proceso se establece una unidad entre la teoría y la práctica, abandonando los sesgos positivistas y la supuesta dicotomía con que se han abordado ambas perspectivas, pero también un diálogo entre los saberes producidos por uno u otro campo. Un planteamiento sociocrítico refuerza la visión mediadora de la teoría y la práctica para conducir a un conocimiento siempre en proceso, en avance continuo pero que no se da por acabado, sino que es temporal y revisable. Para ello, hay que entender que el intercambio de pareceres y de ideas como un paso esencial en la investigación a la hora de concretar puntos de vista comunes y compartidos. Se trata de otro proceso social, ya que el conocimiento tendrá significación si es oportuno, necesario y valorado en lo colectivo. No podemos olvidar que tanto la investigación como la acción marcan modos, reglas y prácticas que, dentro del planteamiento sociocrítico, no son nunca neutrales, sino que contienen ideología y formas políticas. En este sentido, la participación en el proceso investigativo y de acción es en sí misma una posición política de compromiso con el cambio y con la sociedad.

En el caso específico del feminismo, Barbara Biglia (2005) presenta la Investigación Acción Feminista (IAF) a través de los principios que la constituye en 
su compromiso para el cambio social, al margen de la división entre lo público y lo privado, a través de una relación dinámica entre la teoría y la práctica, asumiendo las responsabilidades y una perspectiva situada, se valoran las subjetividades como agencias, se asume que el saber no tiene una lógica propietaria, se afrontan las dinámicas de poder del proceso, que será reflexivo y modificable porque validará el conocimiento a través de diferentes métodos.

\section{Modelos de investigación feminista}

La investigación feminista coincide con la perspectiva humanista de la investigación en el enfoque general, aunque realmente se caracteriza por estar orientada por la propia teoría del feminismo que se desarrolla como una práctica interactiva y dialógica. Reinharz (1983) la define según estos supuestos, pero también por su afán de representar a la diversidad humana, ya que establece una relación directa entre las personas que participan en el proyecto investigador para producir cambios sociales.

\section{TABLA 1}

\section{Modelos de investigación (Reinharz, 1983, en McDowell, 2000)}

\begin{tabular}{|c|c|c|}
\hline & Convencional o patriarcal & Alternativo o feminista \\
\hline $\begin{array}{r}\text { Unidad } \\
\text { de estudio }\end{array}$ & Con definicion previa o hipotesis & $\begin{array}{l}\text { Los hechos naturales se insertan } \\
\text { en los contextos }\end{array}$ \\
\hline Enfoque & Limitado, especifico y exclusivo & Amplio e inclusivo \\
\hline Datos & $\begin{array}{l}\text { Informes sobre conductas, } \\
\text { cuestionarios y archivos }\end{array}$ & $\begin{array}{l}\text { Sentimientos, conducta, } \\
\text { pensamientos, intuiciones }\end{array}$ \\
\hline $\begin{array}{r}\text { Temas } \\
\text { de estudio }\end{array}$ & $\begin{array}{l}\text { Asuntos manejables, según su } \\
\text { contribución a la disciplina } \\
\text { o especialización }\end{array}$ & $\begin{array}{l}\text { Problemas sociales significativos } \\
\text { más que referidos en la } \\
\text { literatura especializada }\end{array}$ \\
\hline Método & Diseño previo & $\begin{array}{l}\text { Determinado por las } \\
\text { caracteristicas del campo }\end{array}$ \\
\hline
\end{tabular}




\begin{tabular}{|c|c|c|}
\hline & Convencional o patriarcal & Alternativo o feminista \\
\hline Validez & Pruebas, evidencias, reproducible & $\begin{array}{l}\text { Completo, verosimil, ilustrativo, } \\
\text { sensible a la experiencia }\end{array}$ \\
\hline $\begin{array}{l}\text { Campo } \\
\text { teórico }\end{array}$ & Determina la investigación & Surge de la propia investigación \\
\hline $\begin{array}{l}\text { Análisis } \\
\text { de datos }\end{array}$ & $\begin{array}{l}\text { Procede de la lógica deductiva } \\
\text { en su conjunto }\end{array}$ & $\begin{array}{l}\text { Se realiza durante el estudio } \\
\text { y puede cambiar }\end{array}$ \\
\hline $\begin{array}{r}\text { Manipulación } \\
\text { de datos }\end{array}$ & Análisis estadistico & $\begin{array}{l}\text { Creación de gestalt y pautas } \\
\text { de significado }\end{array}$ \\
\hline $\begin{array}{r}\text { Objetivo } \\
\text { investigativo }\end{array}$ & Probar hipotesis & $\begin{array}{l}\text { Desarrollo de conocimiento } \\
\text { mediante descripciones } \\
\text { y conceptos fundados }\end{array}$ \\
\hline $\begin{array}{l}\text { Formato de la } \\
\text { presentación }\end{array}$ & $\begin{array}{l}\text { Informe de investigación a partir de } \\
\text { hipótesis y con datos recopilados }\end{array}$ & $\begin{array}{c}\text { Historia, descripción con } \\
\text { conceptos nuevos y documentación } \\
\text { del proceso }\end{array}$ \\
\hline Fracasos & $\begin{array}{c}\text { Insignificancia estadistica } \\
\text { o desacuerdos }\end{array}$ & El proceso no puede ilustrar el tema \\
\hline Valores & $\begin{array}{l}\text { La actitud de la investigación } \\
\text { carece de importancia, no se } \\
\text { reconoce ni se analiza }\end{array}$ & $\begin{array}{l}\text { La actitud se reconoce, se } \\
\text { investiga, se analiza, } \\
\text { demuestra y califica }\end{array}$ \\
\hline
\end{tabular}

Con el estudio espacial y geográfico, Linda McDowell (2000) destaca el estudio de las geografías feministas, para obtener un diagnóstico del poder desde la interpretación espacial como un método del cuestionamiento de la división del trabajo, de la producción y de la reproducción, del bienestar o de las cuestiones humanas y colectivas. Afloran así dimensiones ausentes en el positivismo. Se obtiene una radiografía de la realidad multidimensional y compleja, fruto de la interpretación plural con la que abordar el descentramiento de las jerarquías en los diferentes ámbitos para la integración de valores y de la complejidad de la realidad y de la sociedad. 
TABLA 2

\section{Vinculaciones de la investigación (Reinharz, 1983, en McDowell, 2000)}

\begin{tabular}{|c|c|c|}
\hline & Convencional o patriarcal & Alternativo o feminista \\
\hline $\begin{array}{l}\text { Papel en } \\
\text { relación con } \\
\text { el entorno }\end{array}$ & $\begin{array}{l}\text { Se pretende el control de las } \\
\text { condiciones de la investigación }\end{array}$ & $\begin{array}{l}\text { Apertura, inmersión, trabajo } \\
\text { apegado al medio }\end{array}$ \\
\hline $\begin{array}{l}\text { Papel en } \\
\text { relación con } \\
\text { los sujetos }\end{array}$ & Distanciamiento & Implicación, compromiso, participación \\
\hline $\begin{array}{r}\text { Papel } \\
\text { como persona }\end{array}$ & Irrelevante & $\begin{array}{l}\text { Relevante y en cambio durante } \\
\text { el proceso }\end{array}$ \\
\hline $\begin{array}{l}\text { Influencia en } \\
\text { el investigador }\end{array}$ & Irrelevante & $\begin{array}{l}\text { Anticipada, registrada, } \\
\text { comunicada y evaluada }\end{array}$ \\
\hline
\end{tabular}

Desde este punto de vista, la metodología feminista es una metodología alternativa que interroga permanentemente los valores ignorados por el positivismo, porque son una fuente de conocimiento de igual o de mayor potencia para la interpretación de la realidad, la visión de lo complejo frente a la simplificación esquemática de estos métodos mayoritarios, que suponen que los abordajes científicos, impersonales y supuestamente objetivos se hacen sólidos en el control de los hechos y en la producción de patrones y principios con pautas de investigación. En cambio, con una estrategia alternativa se incluye lo racional e intuitivo en el proceso, y se reconoce a las personas que participan en la investigación por sus aportaciones y por el valor de la subjetividad y los elementos personales en el proceso. Es, por tanto, una forma más precisa, adaptada a los fenómenos y situaciones singulares, a las explicaciones concretas en el estudio de los casos, ya que se busca la comprensión de los fenómenos que incluyen elementos artísticos y singulares, el valor de la intuición y las emociones. 
TABLA 3

Aspiraciones de los métodos de investigación (Reinharz, 1983, en McDowell, 2000)

\begin{tabular}{|c|c|}
\hline Métodos mayoritarios & Métodos alternativos \\
\hline Racionales en investigación y análisis & Mezcla racional e intuitiva \\
Cientificos, impersonales, objetivos & Preciso, artístico, personal, con mezcla \\
objetiva y subjetiva
\end{tabular}

Una temática recurrente dentro del campo de la comunicación son las formas de representación de lo social que, en su análisis de género, muestran siempre el refuerzo del orden establecido y la sexualización de colectivos y de mujeres, por oposición diferencial a una búsqueda necesaria de imágenes alternativas de la diferencia. Se hace así explícita la tendencia generalizada a detener el análisis de género en la reproducción y no en la producción (Benítez-Eyzaguirre, 2016, pág. 20) y, por tanto, a reforzar la lógica de la división espacial del poder.

El diseño metodológico debe atender al criterio de género de tal forma que la investigación previa a la planificación contemple las diferencias necesarias para atender a los distintos perfiles que integran una comunidad: la desagregación de datos es esencial para la mejora de la calidad investigativa. Este planteamiento integrador se presta al diálogo y el debate, en un contexto horizontal y participativo, desde la investigación a pasos posteriores como el diseño, la gestión y la evaluación con criterios idénticos y coherentes, con una visión colectiva por encima de la individual. Su logro solo es realizable si en la transformación se contempla y se insiste en la apropiación de la comunicación, de los instrumentos, en el empoderamiento tanto individual como colectivo de la voz propia como parte de la transformación del pensamiento en acción, como una muestra de la dimensión política de la comunicación. 


\section{Bibliografía}

Araiza, Alejandra (2013). De la política de la localización a los conocimientos situados. Notas para la creación de una ciencia feminista. En Liévano, Marta, \& Duque, Marina (comps.), Subjetivación femenina: investigación, estrategias y dispositivos críticos (pp. 163-191). Monterrey, México: Ediciones UANL, Colección Tendencias. Battochinio S. (2014). Transformaciones de la movilización social a través de la red. El caso de Anonymous. Tesis de maestría. Universidad Complutense de Madrid.

Benhabib, Seyla (2006). El Ser y el Otro en la ética contemporánea. Feminismo, comunitarismo y posmodernismo. Barcelona: Gedisa.

Benítez-Eyzaguirre, Lucía (2016). Comunicación y género: producción, espacio y poder. RIDC. Revista Internacional de Comunicación y Desarrollo, 1(3), 1923. Galicia, España: Universidad de Santiago de Compostela. https://doi. org/10.15304/ricd.1.3.3073

Biglia, Barbara (2005): Narrativas de mujeres sobre las relaciones de género en los movimientos sociales. (Tesis de doctorado). Universidad de Barcelona.

Biglia, Barbara, \& Jiménez-Pérez, Edurne (2012). Conformidades y disconformidades en habitar los márgenes de la investigación. Barcelona: CIDOB. Recuperado de https://www.cidob.org/content/download/59124/1542348/version/1/file/103116_BARBARA\%20BIGLIA_CAST.pdf

Bonder, Gloria (2007). Género, TIC/Sociedad de la Información en Iberoamérica. Actividad preparatoria del evento paralelo "Las políticas de paridad de género en la Sociedad de la Información: Nuevas agendas, Nuevas alianzas". X Conferencia sobre la Mujer de América Latina y el Caribe -CEPAL- Quito, Ecuador, 6 al 9 de agosto 2007. Cátedra regional UNESCO Mujer, Ciencia y Tecnología en América Latina. Buenos Aires, Argentina: Flacso. Recuperado de http://mujeresenred.net/ IMG/pdf/INFORME_FINAL_foro_tic_2007.pdf

Butler, Judith (2015). Cuerpos aliados y lucha política. Hacia una teoría performativa de la asamblea. Barcelona: Paidós. 
Castells, Manuel (2005). La era de la información. Vol. 1. La sociedad red. Madrid: Alianza Editorial.

Castles, Stephen (2010). Comprendiendo la migración global: una perspectiva desde la transformación social. Relaciones internacionales, 14, 141-169. Recuperado de https://revistas.uam.es/index.php/relacionesinternacionales/ article/download/5020/5481

Comisión Europea (2011). Manual "El género en la investigación". European Commission, Research \& Innovation y Ministerio de Ciencia e Innovación. Recuperado de http://www.ciencia.gob.es/stfls/MICINN/Investigacion/FICHEROS/ El_genero_en_la_investigacion.pdf

Corsani, Antonella (2006). Políticas de saberes situados. Emanciparse de la epistemología de la economía política y de su crítica. En Legarreta Iza, Matxalen; Ávila Cantos, Débora, \& Pérez Orozco, Amaia (coords.), Transformaciones del trabajo desde una perspectiva feminista: Producción, reproducción, deseo, consumo. Madrid: Tierradenadie, 29-48.

Da-Silva-Moreira, Artur-Carlos (2004). Cultura mediática y educación. En Zamora, José-Antonio (coord.), Medios de comunicación. Información, espectáculo, manipulación. Estella (Navarra): EVD.

Diani, Mario (1992). The Concept of Social Movement. The Sociological Review, 40(1), 1-25. https://doi.org/10.1111\%2Fj.1467-954X.1992.tb02943.x

Durston, John, \& Miranda, Francisca (2002). Experiencias y metodología de la investigación participativa. Chile: Naciones Unidas.

Eizaguirre, Marlen, \& Zabala, Néstor (2006). Investigación-acción participativa (IAP). Diccionario de Ayuda Humanitaria y Cooperación al Desarrollo. HEGOA, Universidad del País Vasco. Recuperado de http://www.dicc.hegoa.ehu.es/listar/ mostrar/132

Ema-López, José-Enrique (2006). “Límites y posibilidades de prácticas políticas feministas de la localización” en Legarreta Iza, Matxalen; Ávila Cantos, Débora; Pérez Orozco, Amaia (coords.), Transformaciones del trabajo desde una perspectiva feminista: Producción, reproducción, deseo, consumo. Madrid: Tierradenadie, pp. 105-124. 
Freire, Paulo (1975). Pedagogía del oprimido. Madrid: Siglo XXI.

García-Selgas, Fernando (1995). "Reapropiación del discurso científico. Las resistencias de lo fluido". En Haraway, Donna J., Ciencia cyborgs y mujeres: la reinvención de la naturaleza. Madrid: Cátedra, pp. 19-32.

Gregorio-Gil, Carmen (1998). Migraciones de género. Su impacto en las relaciones de género. Madrid: Narcea de Ediciones.

Guerra-Palmero, María-José (2007). ¿Es inevitable el etnocentrismo? Aportaciones feministas a un debate en curso. Thémata. Revista de filosofía (39), pp. 59-64. Recuperado de https://dialnet.unirioja.es/servlet/ articulo codigo $=3310299$ \&orden $=270157$ \&info $=$ link

Hall, Budd L. (1983). Investigación participativa, conocimiento popular y poder: una reflexión personal. En Vejarano, Gilberto (comp.), La investigación participativa en América Latina. Antología (pp. 15-34). Pátzcuaro, México: Crefal, Biblioteca digital. Recuperado de https://studylib.es/doc/8615206/la-investigaci\%C3\%B3nparticipativa-en-am\%C3\%A9rica-latina.-antolog\%C3\%ADa

Haraway, Donna J. (1995). Ciencia, cyborgs y mujeres. La reinvención de la naturaleza. Madrid: Cátedra.

Harding, Sandra (1987). Introduction: Is there a feminist method? En Harding, Sandra (ed.) Feminism and Methodology: Social science issues (pp.1-11). Indianapolis: Indiana University Press.

Harding, Sandra 1995 (1986). Feminismo y ciencia. Barcelona: Morata.

Hardt, Michael \& Negri, Antonio (2004). Multitud. Guerra y democracia en la era del Imperio. Barcelona: Debate

Harvey, David (1990). La condición de la posmodernidad. Buenos Aires, Argentina: Amorrortu.

Lefebvre, Henri (2013). La producción del espacio. Madrid: Capitán Swing.

Johnson, Steven (2003). Sistemas emergentes o qué tienen en común hormigas, neuronas, ciudades y software. Madrid: Turner- Fondo de Cultura Económica. 
Manovich, Lev (2014). El software toma el mando. Barcelona: UOC

Massey, Doreen (2012). Espacio, lugar y política en la coyuntura actual. Urban, (4), 7-12. Recuperado de https://dialnet.unirioja.es/descarga/articulo/4974974.pdf

---- (1992). Politics and space/time. New Left Review, 1 (196), 65-84.

---- (2005). La filosofía y la política de la espacialidad: algunas consideraciones. En Arfuch, Leonor (comp.), Pensar este tiempo: espacios, afectos, pertenencias. Buenos Aires, Argentina: Paidós, 101-128.

McDowell, Linda (2000). Género, identidad y lugar. Valencia: Cátedra.

Melucci, Alberto (1999). Acción colectiva, vida cotidiana y democracia. Ciudad de México: el Colegio de México, Centro de Estudios Sociológicos. Recuperado de: http:// www.cervantesvirtual.com/descargaPdf/accion-colectiva-vida-cotidiana-ydemocracia-924292/

Melucci, Alberto (1996). Challenging the codes. Collective action in the information age. Cambridge: University Press.

(1994). Asumir un compromiso: identidad y movilización en los movimientos sociales. Zona Abierta (69), 153-180.

Merejo, Andrés (2015). Epistemología digital. Realis, 5(2), 156-164. Recuperado de https://periodicos.ufpe.br/revistas/realis/article/download/8848/8823

Millman, Marcia, \& Kanter, Rosabeth-Moss (eds.) (1975). Another Voice: Feminist Perspectives on Social Life and Social Science. Nueva York: Anchor Books.

Mouffe, Chantal (1995). Post-Marxism: democracy and identity. Environment and Planning D: Society and Space 13 (3), 259-265. https://doi.org/10.1068/d130259

Moyá, Isabel (2009). Del azogue y los espejos: nexos entre la teoría de género y la teoría de la comunicación. XIII Encuentro latinoamericano de facultades de Comunicación Social. La comunicación en la sociedad del conocimiento: desafíos para la universidad. Palacio de Convenciones de La Habana, Cuba Del 19 al 22 de octubre de 2009. www.felafacs 
Oslender, Ulrich (2002). Espacio, lugar y movimientos sociales hacia una 'espacialidad de resistencia'. Scripta Nova: Revista electrónica de geografía y ciencias sociales, VI(115), 105-132. Recuperado de http://www.ub.edu/geocrit/ sn/sn-115.htm

Pérez-Orozco, Amaia (2006), Perspectivas feministas en torno a la economía: el caso de los cuidados. Madrid: Consejo Económico y Social. Recuperado de https://porunavidavivible.files.wordpress.com/2012/09/perez-orosco.pdf

Radcliffe, Sarah A. (1993). Women's Place / El Lugar de Mujeres: Latin America and the Politics of Gender Identity. En Keith, Michael, \& Pile, Steve (eds.), Place and the Politics of Identity. London: Routledge, 102-116. https://doi. org/10.4324/9780203016695

Raschke, Joachim (1994). Sobre el concepto de movimiento social. Zona Abierta (69), 121-134.

Reinharz, Shulamit (1983). Experiential Analysis: A Contribution to Feminist Methodology. En Bowles, Gloria, \& Duelli-Klein, Renate (eds.). Theories of Women's Studies. Boston: Routledge \& Kegan Paul.

Rovira Sancho, Guiomar (2018). El devenir feminista de la acción colectiva: las redes digitales y la política de prefiguración de las multitudes conectadas. Teknokultura, 15(2), 223-240. https:// doi.org/10.5209/TEKN.59367

Sassen, Saskia (2003). Contrageografías de la globalización. Género y ciudadanía en los circuitos transfronterizos. Madrid: Traficantes de sueños. Recuperado de https:// www.traficantes.net/sites/default/files/pdfs/Contrageografias $\% 20$ de $\% 20$ la\%20globalizaci\%C3\%B3n-TdS.pdf

Scolari, Carlos (2018). Las leyes de la interfaz: diseño, ecología, evolución, tecnología. Barcelona: Gedisa.

Ursua, Nicanor (2013). "e» - Epistemología: un desafío y una respuesta filosófica al mundo digital. Daimon. Revista Internacional de filosofía (61), 55.74. doi: 10.6018/daimon/155871

Wajcman, Judy (2006). El tecnofeminismo. Madrid: Cátedra, Colección Feminismos. 